\title{
SOBRE BESTAS E MAPAS: NOTAS INTRODUTÓRIAS SOBRE A VIRADA ANIMAL NA GEOGRAFIA HUMANA CONTEMPORÂNEA ${ }^{1}$
}

\author{
PABLO CAMPOS LEAL ${ }^{2}$
}

\section{Interdições}

Ao contrário do que possa parecer numa primeira olhada de sobrevoo os animais não-humanos estão presentes - mesmo que sob perspectivas epistêmicas e éticas das mais variadas - desde há muito tempo, na Geografia. Evitando as controvérsias e os perigos ético-políticos sobre quando, onde e com quem se origina ${ }^{3}$ a Geografia, podemos destacar que

${ }^{1}$ Esse artigo faz parte de um trabalho de maior envergadura, minha dissertação de mestrado, realizada através do Programa de Pós-Graduação em Bioética e Ética Aplicada (PPGBIOS-UFF) cujo título é Territórios Animais: Uma Investigação Sobre o Estatuto Moral dos Animais Não-Humanos na Geografia Humana Contemporânea, sob orientação de Rita Leal Paixão. Agradeço desde já as contribuições e o caloroso incentivo para que escrevesse esse artigo, por parte do professor Rogério Haesbaert. Agradeço também ao professor Rafael Haddock Lobo pelas contribuições críticas e ajuda na compreensão e construção de uma filosofia bestiamente desconstrutora.

${ }^{2}$ Graduado em Geografia pela Universidade Federal Fluminense e Mestre em Bioética e Ética Aplicada pelo PPGBIOS (UFF, UFRJ, UERJ e Fiocruz)

${ }^{3}$ Colocamo-nos aqui no rastro da crítica nietzschiana da História, sobretudo no que diz respeito a sua crítica à origem, posteriormente desenvolvida pela desconstrução de Derrida e pela crítica genealógica de Foucault e também de Deleuze e Guattari. Assim, para nós, a origem é um "broto metafísico que torna a arrebentar quando se considera a história, e faz acreditar que no início de todas as coisas está o mais valioso e essencial" (NIETZSCHE, 2008: 164). De modo que temos de negar "a exigência absoluta [da metafísica ocidental] de procurar a origem, o centro, o fundamento, o princípio e etc." (DERRIDA, 2011: 418). Não nos interessa buscar o grande fundador, o pai ou qualquer outro pé-grande metafísico fundacional da Geografia, ao contrário, interessa a "emergência", isto é, "a entrada em cena das forças; [...] sua interrupção, o salto pelo qual elas passam dos bastidores para o teatro, cada uma com seu vigor e sua própria juventude." (FOUCAULT, 2012a, p. 67). Emergência que também pode ser entendida como "um meio, uma atmosfera, uma atmosfera ambiente" (DELEUZE; GUATTARI, 
Eratóstenes (285-205 - a.C.) se preocupou em estudar o papel dos animais na diferenciação cultural entre a Etiópia e o Egito e, na mesma linha, Estrabão (63 a.C.- 24 d.C) constatou a importância da domesticação de cavalos para o desenvolvimento bélico e geopolítico da Ibéria (URBANIK, 2012), atestando assim, a muito antiga preocupação com o papel dos animais não-humanos na diferenciação cultural do espaço geográfico, por parte de seus estudiosos.

Mesmo no âmbito daquela geografia mais amplamente aceita - pelos geógrafos e historiadores da geografia ${ }^{4}$-, isto é, àquela que se desenvolveu no contexto de institucionalização dos padrões da ciência moderna, em fins de século XIX, sobretudo na Alemanha e França, até nessa os animais nãohumanos ainda eram considerados como parte do escopo epistêmico e de objeto da Geografia. Ratzel, por exemplo, estudou o impacto do avanço territorial civilizacional, afirmando - sob uma perspectiva perigosamente hobbesiana - que quase sempre os resultados eram extinção total da vida animal (1914: 481). Brunhes, no seu Geografia Humana, considerou a domesticação dos animais como um "fato essencial de Geografia Humana" (1962: 87). La Blache considerou a criação e o uso dos animais nãohumanos como importantes elementos para a construção material do progresso civilizatório (LEAL, 2013b: 309). Já Reclus, o geógrafo anarquista e vegetariano, via com um olhar muito crítico a exploração animal nos abatedouros e vislumbrava uma espécie de cidadania global transespécie como utopia libertária (LEAL, 2011).

Mas de forma mais organizada, em termos de método e de rigor epistemológico, os animais não-humanos só entram na Geografia no século XX. Em 1913 Marion Newbigin publica seu livro Animal Geography, focando na distribuição espacial dos animais não-humanos ao redor do globo (WOLCH, 2002: 723). Essa perspectiva, muito próxima do que hoje se conhece como biogeografia animal, também era conhecida como zoogeografia, tendo importantes nomes como G. S. Cansdale e anteriormente Karl Mobius e Eagle Clarke (Ibidem). Posteriormente, sob a

2009: 125). Dito de outro modo, pensar os contextos materiais nos quais forças antagônicas, conflituosas, contingentes, microfísicas e sutis, territorializam-se, produzindo um caldeirão político-epistêmico que permite a emergência de novas paisagens históricas. ${ }^{4}$ Nos referimos aqui aos estudos já clássicos de Capel $(1983$; 1989) e Claval (1974; 2006), que estabelecem a Geografia nos marcos das institucionalizações prussianas/alemãs e posteriormente francesas, em fim de século XIX, destacando os nomes de Friedrch Ratzel e Vidal de La Blache. 
forte influência do importantíssimo Seeds, Spades, Hearths and Herds, de Carl Sauer, publicado em 1952, emerge uma nova perspectiva de estudo dos animais em Geografia. O foco já não era mais compreender a distribuição espacial dos animais, mas compreender o papel cultural dos animais, especificamente através da domesticação, na construção de "paisagens culturais" (EMEL; WILBERT; WOLCH, 2002: 408). Essa perspectiva ficou conhecida como "geografia animal cultural" (WOLCH, 2002: 723), em função da influência da ecologia cultural saueriana, seguida por importantes nomes como Frederick Simoonses, E. Isaac e Charles Bennet (WOLCH, 2002; PHILLO; WOLCH, 1998). E em meados dos anos 1990, emerge uma outra geografia animal, focando agora nas dimensões ético-políticas e simbólico-culturais das interações animaishumanos do ponto de vista da sua geograficidade (PHILO; WILBERT, 2000: 05). Os saltos que ocorrem aqui se dão mais por rupturas, descontinuidades e emergências, do que por continuidades teleológicas, permanências e origens. De tal modo que os recortes em primeira (Zoogeografias), segunda (Geografias Animais Culturais) e terceira onda (Novas Geografias Animais) das geografias animais, propostos por Urbanik (2012), se mostram insuficientes, já que retomam a "análise dos nascimentos surdos, das correspondências longínquas, das permanências que se obstinam sob mudanças aparentes" (FOUCAULT, 2010: 156).

Apesar de recente, a produção de geógrafos animais já é enorme, tanto sob o ponto de vista quantitativo, quanto sob o das contribuições ao debate epistemológico em Geografia. Longe de esgotar o tema, propomos aqui trazer algumas das inúmeras contribuições das geografias animais, selecionando apenas alguns pontos que julgamos mais importantes em termos de introdução a esse campo, ainda praticamente inexplorado no âmbito da Geografia brasileira (e talvez latino-americana).

Preliminarmente é importante dizer do desafio inicial das geografias animais para se estabelecerem enquanto um campo coerente $\mathrm{e}$ emblemático, em termos de potência crítica e epistêmica na Geografia Humana: trata-se da crítica do conceito de natureza. Depois, destacaremos os quadros nos quais emergiram essas "novas geografias animais" (URBANIK, 2012: 36), focando nos pioneirismos e nos seus principais "acontecimentos discursivos" (FOUCAULT, 2012b: 55). Em seguida, realçaremos as principais bases político-filosóficas das geografias animais. $\mathrm{Na}$ penúltima parte trataremos das críticas antiantropocêntricas e antiespecistas das geografias animais ao escopo epistêmico da Geografia Humana contemporânea. E, por fim, faremos algumas considerações a 
respeito dos limites e potências de uma geografia animal que ainda se coloca enquanto um projeto recente e em construção.

\section{Um Deserto Chamado Natureza}

Em fins dos anos 1970 a Geografia Humana anglo-saxônica se volta para as temáticas ecológicas, sobretudo no contexto de uma crítica humanista/fenomenológica e marxista das consequências do capitalismo industrial ocidental e seus impactos nos sistemas ecológicos. No seu Topofilia, de 1974, Tuan se questionava: "quais são nossas visões de meio ambiente físico, natural e humanizado?", quais seriam, portanto, os nossos "ideais ambientais" (2012: 15). Um certo holismo marxista era timidamente expressado por Massimo Quaini em Geografia e Marxismo, do mesmo ano, sobretudo quando este afirmava que elementos para a superação desse mal-estar ecológico já estavam contidos nas sagradas escrituras: "[...] em Marx e Engels, podemos encontrar todos os elementos para uma crítica radical de uma concepção das relações entre homem [sic] e natureza" (2002: 18 - grifo adicionado). Uma visão marxista um pouco mais sofisticada é apresentada em Desenvolvimento Desigual, de Neil Smith, publicado em 1984. Para Smith, o capitalismo não é só responsável pela destruição física da natureza, mas pela mudança de seus significados, de modo que "a transformação global da natureza realizada pelo capitalismo industrial domina tanto o consumo físico quanto o intelectual da natureza" (1988: 27).

Apesar disso, essas críticas ecológicas - tanto de matriz humanista/fenomenológica, quanto marxista - não se deram sem impasses e problemas. E, sem dúvida, o maior deles foi o limite teórico estabelecido internamente pela categoria de natureza. Nesse sentido, um desafio inicial para o estabelecimento das geografias animais enquanto um campo de pesquisa coerente, crítico e emblemático, foi a necessidade de varrer o conceito de natureza do terreno para dar espaço a uma crítica em termos de ética animal. A natureza funcionava como um "conceito obstáculo", de maneira semelhante como foi com o de região para a crítica inicial de Lacoste (2009: 59), no sentido de que impedia que outras questões fossem colocadas.

É importante destacar que apesar do especismo estar vigorosamente "territorializado" (DELEUZE; GUATTARI, 2009) na Geografia Humana, não se trata de maneira nenhuma de uma exclusividade sua, já que este 
abarca as formações socioespaciais ocidentais, estando presente massivamente em todas as Ciências Humanas, nas quais, polêmicas à parte, a Geografia Humana se insere. E como bem expressaram Emel e Wolch:

A teoria social permanece resolutamente antropocêntrica. Animais não-humanos tendem a ser subsumidos dentro dos debates sobre natureza/cultura ou, mais geralmente, sobre ambiente. Essas discussões raramente envolvem a questão da senciência animal ou os significados da ação humana nas vidas e mundos não-humanos. Os animais são significantes, e têm suas vidas negadas. Os animais são o último Outro. (1995: 632).

A natureza era tomada como um já dado, como um elemento vazio e pré-discursivo sobre o qual a ação humana se desenvolve, de modo que ela "ainda permanece um conceito muito pouco definido [...]. Ao ler a maioria dos textos geográficos, pode-se nunca tomar conhecimento de que a natureza é povoada por criaturas sencientes; os animais foram simplesmente confinados na caixa preta ou dissolvidos nos sistemas ecológicos ou de produção" (EMEL; WOLCH, 1998: XV-XVI). Kay Anderson também ressaltava o caráter pitoresco do especismo, que assimila a complexidade viva e senciente das formas de vida não-humanas na "caixa preta" que é a categoria de "natureza" (1998: 30). É necessário, então, afirmar que o interdito animal ${ }^{5}$ na Geografia Humana contemporânea se deu também pela subsunção da vida animal não-humana à categoria de natureza, como também percebeu Philo, ao notar que a Geografia, de forma geral, "negligenciou os animais como objetos de estudos característicos, frequentemente subsumindo-os em discussões mais amplas sobre natureza e ambiente, raramente fazendo deles uma questão especial e merecedores de considerações especiais." (1998: 53). Emel também percebeu esse processo e, ao contrário da maioria das novas geógrafas animais, que desertaram do conceito de natureza, preferiu reafirmar que "para muitos de nós a natureza não está morta" (1998: 112). Essa geografia, que se levanta numa crítica ecológica, ainda parece estar presa àquela cosmovisão da revolução científica pós-renascentista que vê a "natureza como uma realidade [meramente] material e externa" (MICHEL, 1998: 164). Para Emel, Wilbert e Wolch, a tarefa consiste em "abrir a

\footnotetext{
${ }^{5}$ Pensamos interdito como uma interdição discursiva. Algo que está ao mesmo tempo interditado e inter(entre)dito, mais uma vez no rastro genealógico de Foucault (2012b: 9).
} 
'caixa preta' da Natureza", de modo a conseguir espaço para a afirmação da 'subjetividade animal'" (2002: 408).

É justamente no contexto de uma entrada crítica ecológica na Geografia Humana, e combatendo o vazio ético nas abordagens de Natureza - operando um "descentramento" (DERRIDA, 2011: 410) dessa categoria -, que "emerge" (FOUCAULT, 2012b: 67) o que chamamos de virada animal na Geografia Humana contemporânea.

\section{Emergências}

Em meados dos anos 1990 um movimento amplo, heterogêneo e, por vezes, contraditório emerge do âmbito da Geografia Humana anglo-saxã para questionar o próprio "Humano" dessa Geografia (WHATMORE, 1999). Esse questionamento se insere em um contexto de transformações e turbulências nas próprias renovações políticas no interior das ciências humanas, como também de transformações político-culturais mais amplas. A construção de um campo novo, amplo e interdisciplinar chamado Estudos Animais, Estudos Animais Críticos e Estudos Animal-Humano, e a anterior construção de uma Ética Animal nas bases das críticas ao paradigma antropocêntrico e especista de exploração animal, por parte de Singer (2010), Regan (2006), Adams (2012), tiveram também o seu impacto na Geografia (ANDERSON, 1997; URBANIK, 2012). Numa escala mais ampla, a luta política e militante contra a exploração animal por parte de grupos como PETA (Pessoas pelo Tratamento Ético dos Animais ${ }^{6}$ ), British Vegan Society (Sociedade Vegana Britânica), ALF (Frente de Libertação Animal), Sea Shepherd (Pastores do Mar), entre outros, gerou uma série de questionamentos sociais na forma como a sociedade capitalista industrial ocidental se relaciona com as formas de vidas não-humanas, o que também se refletiu no campo da Geografia (WOLCH, 2002: 725). E é esse quadro complexo que gera a "atmosfera ambiente" (DELEUZE; GUATTARI, 2009: 125) para surgir as "novas geografias animais" (URBANIK, 2012: 36), as "geografias para-além-do-humano" (GRIFIN, 2010: 452) e/ou "geografias híbridas" (WHATMORE, 2002).

Citaremos, a fim de sermos mais específicos, quatro grandes "acontecimentos discursivos" (FOUCAULT, 2012b: 55) que nos ajudam a compreender melhor o contexto de "emergência" (FOUCAULT, 2012a) da

${ }^{6}$ Essa e as demais traduções do inglês são livres, feitas por nós. 
renovação crítica nas geografias animais. A aparição do número temático da importante revista de Geografia Humana norte-americana Environmental and Planning D: Society and Space, edição de 1995, volume 13 intitulado Bringing the Animals Back in, foi um deles. Trata-se de um número inteiro dedicado a apresentação desse novo campo, trazendo pesquisas empíricas e reflexões teóricas a respeito da espacialidade das relações animais/humanos. Em segundo lugar, temos a realização da conferência Animals, Agency and Geography apresentada durante a conferência anual da Royal Geographical Society, realizada na Universidade de Exceter (Exceter, Inglaterra) em 1997. Cabe ressaltar que esse evento culminou com a publicação do importantíssimo Animal Spaces, Beastly Places: New Geographies of Human/Animal Relations, em 2000, organizado por Chris Wilbert e Chris Philo. Em terceiro lugar temos a publicação de outro marco, Animal Geographies: Place, Politics and Identity in the Nature-Culre Borderlands, em 1998, sob a organização de Jody Emel e Jennifer Wolch. Por fim, a publicação do número especial da importante revista Society and Animals também em 1998 - dedicado às geografias animais -, volume 6, número 2 .

No que diz respeito à definição teórico-conceitual do campo, ainda existem disputas e contradições mas, decerto, alguns consensos. No artigo de abertura do número especial da EPD, Wolch e Emel argumentavam que a tarefa para o campo era "trazer de volta os animais para o nosso entendimento de espaço e lugar, ao focar nas possibilidades de inclusão. Aqui, nós desenvolvemos nossa defesa para uma teoria social transespécie" (1995: 632). E no prefácio de Animal Geographies, afirmavam ainda que as geografias animais deviam "buscar contribuir com o repensar quanto aos animais e sugerir como, através das lentes geográficas, nós podemos trazer os animais para um foco mais claro e para dentro de nosso entendimento da vida social" (1998: xii). Já para Philo, o objetivo era observar "as formas em que esses ordenamentos se conectam com práticas espaciais de inclusão e exclusão dos animais" (1998: 53). Mostrar "os tipos de redes das relações animal-humano", na sua relação com os "espaços e lugares envolvidos", e mais, como espaços e lugares podem variar e alterar a própria natureza dessas relações, seria o objetivo das geografias animais para Philo e Wilbert (2000: 5).

Apesar das diferenças, podemos perceber que a preocupação ética em relação aos animais não-humanos, a crítica latente à negligência com que a Geografia tem tratado esses e, a preocupação em verificar os limites e potências de lugares e espaços para a compreensão das geograficidades 
das relações animais-humanos são algumas das intersecções no campo. Ainda assim, é importante destacar que as diferenças teóricas, metodológicas e mesmo de definição de objeto raramente aparecem como um problema teórico ou político nas geografias animais, é possível afirmar que as diferentes bases teórico-filosóficas e ético-políticas que formam esse campo negam uma pretensão universalista, caracterizando uma diferença potencial em termos epistêmicos e políticos em sua base.

\section{Rastros ${ }^{7}$ Político-Filosóficos}

Como vimos, os embasamentos político-filosóficos e teóricometodológicos nas geografias animais contemporâneas são tão amplos, quanto significativos. Longe de tentar esgotar ou colocar uma análise final e acabada, buscamos aqui somente destacar aquelas perspectivas mais abundantes e expressivas na literatura crítica das geografias animais.

Como primeira abordagem temos as geografias culturais animais. Passando por nomes como Newbigin, Cansdale e Bennet, essas geografias operaram uma ruptura com as geografias animais anteriores, que no início do século XX tratavam de estudar a distribuição dos animais num contexto ecológico e biológico (PHILO, 1988; PHILO; WILBERT, 2000; WOLCH, 2002; WILBERT, 2009; PHILO; WOLCH, 1998). Essa geografia surge examinando "desde os tempos mais remotos, os humanos em seu papel de "dominadores ecológicos"” e os impactos dessa dominação no mundo natural e nas vidas não-humanas (PHILO, 1998: 56). Mas sem dúvidas, seu principal nome foi Carl O. Sauer. No pioneiro Seeds, Spades, Hearths and Herds (Sementes, Espadas, Fornos e Rebanhos), de 1952, Sauer afirmava que sua obra partia "de um interesse há muito desenvolvido no remoto curso da atividade humana, na qual, aqui e lá, pessoas anônimas passaram a manter e criar plantas e animais por vários motivos" (1972: VII). Sauer e sua abordagem caminhavam num sentido de enxergar o papel da domesticação animal na transformação de "paisagens naturais" em

\footnotetext{
${ }^{7}$ Trata-se de um conceito vital para Derrida. Na tentativa nietzschiana de se afastar das origens em História, Derrida entende o rastro como uma alternativa não teleológica e antiuniversalista para se pensar os acontecimentos históricos antecessores, de modo que mesmo assim, o rastro "não é nem um fundo, nem um fundamento, nem uma origem, e que ele não poderia, em nenhum caso, dar lugar a uma ontoteleologia manifesta ou disfarçada" (2001: 59).
} 
"paisagens culturais" (PHILO, 1998). De modo que, para Philo e Wolch essas novas geografias animais se inserem numa "parcial renovação das antigas tradições sauerianas", a tal ponto que elas chamam esse processo de "novas geografias culturais animais" (1998: 107). Ainda mais significativo para a emergência das novas geografias animais é o Dominance and Affection [Domínio e Afeto] de 1984. Embora a obra de Tuan não se configure propriamente no âmbito da geografia animal cultural, é preciso reconhecer que sua preocupação com o ambiente na sua interface com as ações humanas se insere nas preocupações da "ecologia da paisagem" saueriana (CLAVAL, 1999: 64); ainda mais em se tratando da obra anteriormente mencionada, na qual Tuan se propõe a traçar a linha comum que liga "a criação e o treinamento de animais domésticos, o estabelecimento de zoológicos e os empregados domésticos" (1984: 5). Na direção de construir uma geografia que se debruce diretamente sobre as interações animais/humanos, Dominance and Affection parece se constituir como um marco fundamental, uma condição de emergência (FOUCAULT, 2012), ou, um rastro (DERRIDA, 2001) da renovação das geografias animais. Sobre isso, Philo afirma: "há muito me intriga como um possível ponto de partida para repensar a forma na qual os animais podem ser pesquisados por geógrafos humanos" (1998: 51). Que esta seja a frase de abertura de seu texto, apenas atesta o caráter emblemático da obra de Tuan. Para Philo, Tuan parece operar uma nova mudança no estatuto moral dos animais não-humanos na medida em que ele "começa a considerar os animais como um grupo 'social' enredados em uma batalha contra os humanos", possibilitando repensar os animais não-humanos a partir do que alguns geógrafos humanos chamam de "outsider" (1998: 51). Philo e Wolch (1998: 108) destacam "dimensões mais simbólicas do encontro entre humanos e animais", presentes nessa obra.

Como uma segunda base teórico-filosófica temos as críticas daquilo que ficou vulgarmente conhecido como filosofia pós-estruturalista. Primeiramente, há que se atentar para o descontentamento generalizado dos que foram enquadrados nesse rótulo, com destaque para o fato de que quase a totalidade o negou (HARRISON, 2006). Preferimos falar em crítica anti-humanista ${ }^{8}$, tendo em vista a potência do vitalismo filosófico e

\footnotetext{
${ }^{8}$ Basta ver a crítica à subjetividade carnofalogocêntrica e a importância dos animais para Derrida (2004, 2002); a invenção e a contingência humana para Foucault (1967); ou a importância dos devires animais $(2003,2007)$ e a crítica às perniciosidades do humanismo e a "vergonha em ser Homem" (2009) de Deleuze e Guattari.
} 
a crítica viral aos embasamentos do Humanismo Moderno empregado por esses filósofos. No mesmo sentido, Braidotti fala de um "Nomadismo Filosófico" (2006: 144), termo que, mesmo com algum receio, parece simpático. O que mais se realça aqui são os desenvolvimentos de pesquisas em geografia animal pautados nas reflexões de Foucault sobre a governamentalidade e sobre a biopolítica e biopoder (LORIMER; SRINIVASAN, 2013: 334). Holloway et. al. (2012) estudam as manipulações genéticas em bois de abatedouros industriais ingleses a partir da lógica biopolítica. Wilbert ([s.d.]: 102) se propõe a fazer uma análise do controle de aves de granjas industriais infectadas, dentro de uma ótica foucaultiana, observando, por fim, uma correlação entre o discurso da biossegurança e as práticas biopolíticas de controle e gestão calculadas sobre a vida desses animais não-humanos. Wilbert e Philo se utilizam da análise crítica de Foucault sobre a história natural e sobre as ciências humanas para criticarem a "localização conceitual animal em 'estruturas das coisas' mais amplas"” (2000: 06). Uma perspectiva deleuzeana também parece existir no que diz respeito a uma análise de geografia animal sobre conservação e biodiversidade (LORIMER; SRINIVASAN, 2013: 336). Hinchlife, Whatmore e outras utilizam as contribuições de Deleuze e Guattari para pensar a "escritura" das ratazanas na Londres urbana contemporânea (2003: 647); procurando pensar como as territorialidades das ratazanas, na interface com a Londres urbano-capitalista, pode produzir um texto, uma escrita. Hinchlife (2007: 150-161) se utiliza amplamente das reflexões de Derrida para repensar e desconstruir o conceito de animal. Emel e Wolch (1998: 18) corroboram as críticas de Derrida para desconstruir os binarismos ocidentais que instrumentalizam, objetificam ou estereotipificam os animais não-humanos. Apesar desses e alguns poucos outros esforços, as potentes contribuições de Derrida sobre ética animal permanecem pouco aproveitadas dentro da renovação crítica das geografias animais.

As reflexões críticas do ecofeminismo, sobretudo com Val Plumwood, e do feminismo vegano, onde se destaca Carol J. Adams (2012), aparecem como uma terceira perspectiva da renovação das geografias animais. Assim, essa renovação já emerge aliada às feministas que entendem a "importância dos animais" nos processos de "codificação" ligados à "sexualidade e [ao] corpo" (EMEL; WILBERT; WOLCH, 2002: 408). A produção de significados nas "formas em que certas identidades humanas têm sido construídas em relação a certos animais" não pode ser analisada sem a categoria de "gênero", como nos lembra Wilbert (2009: 
122). Numa linha parecida, Wolch percebe que "geógrafos animais têm começado a entender o papel dos animais no desenvolvimento de [...] identidades", relacionadas também com dinâmicas de "gênero". Essa nova "virada" se inspira num encontro múltiplo entre geografia humana e novos desenvolvimentos teóricos, na qual se destaca também o "feminismo" (PHILO; WOLCH, 1998: 107). Utilizando-se da "teoria do referencial ausente" 9 (ADAMS, 2012), Emel e Wolch nos lembram que "as hierarquias alimentícias nas sociedades Ocidentais (que estão se tornando incrivelmente globalizadas) refletem relações de poder patriarcais e classistas, com as comidas animais (especialmente a carne vermelha) no topo da hierarquia" (1995: 634). Emel e Wolch, mais uma vez reconhecem a contribuição das "ecofeministas", que perceberam as "fontes de opressão similares tanto para as mulheres quanto para os animais" (1998: 15).

Os estudos feministas da ciência, principalmente a partir das reflexões de Donna Haraway (1995), aparecem como um quarto importante embasamento. Trata-se basicamente de uma crítica aos desenvolvimentos da tecnociência, no que diz respeito aos seus impactos na natureza, nos animais não-humanos e nas mulheres (HARAWAY, 1995). Destacando as contribuições dos estudos feministas da ciência para as geografias animais, Hinchlife afirma que "mobilizando monstros, ciborgues e coiotes [...] Haraway expande seu trabalho para explorar possíveis alternativas às atuais relações entre espécies. É uma tentativa de traçar caminhos para outras artes de viver." (2007: 151). Para Emel e Wolch, o trabalho de Haraway é importante para as geografias animais pois mostra a "indeterminação que acompanha os esforços de construir a humanidade a partir do animal como o outro, e vice versa.", dialogando também a "ciência primata" com as bordas da "política" e do "social" (1998: 19). A "ciência animal", com a qual Haraway dialoga, também tem contribuições para as novas geografias animais, já que esse diálogo

\footnotetext{
${ }^{9}$ Trata-se de uma estratégia semiótico-política das tecnologias especistas que mascaram as práticas especistas ao excluir os animais não-humanos de qualquer forma de representação ou simbolismo, criando assim, um vazio de significado no qual os animais passam a não mais serem enxergados (principalmente em termos éticos), e assim, podem ser facilmente instrumentalizados. Nas palavras de Adams: "Uma vez que a existência da Carne é desligada da existência de um animal que foi morto para se tornar 'carne', esta fica desancorada do seu referencial original (o animal), tornando-se, em vez disso, uma imagem que não está ligada a nada, imagem essa usada frequentemente para refletir o status feminino, assim como o dos animais. Os animais são o referencial ausente no ato de comer carne." (2012: 24)
} 
consiste "nas histórias cruzadas de duas espécies, como também [n]as múltiplas formas nas quais as pessoas e cães contemporâneos se tornam o que são em relação um ao outro" (LORIMER; SRINIVASAN, 2013: 336). E importante também lembrar a crítica de Haraway aos pressupostos especistas, sexistas e irresponsáveis da ciência moderna, como faz Anderson, ao notar que ela não passa de uma "'perspectiva parcial' pautada em várias estratégias de exclusão, separação espacial, estereotipificação de mulheres, pessoas racializadas, animais não-humanos e a "natureza' de uma forma geral" (1998: 31). Emel, a partir de Haraway, questiona os binarismos da ciência moderna como parte de uma tradição e dinâmica mais ampla que visa subalternizar um dos termos da hierarquia, mostrando assim como a dicotomia animal/humano cumpriu um papel na expansão urbana americana e na extinção em massa de lobos que ameaçavam tal dinâmica (1998: 92).

Aqui aparecem as críticas e os estudos pós-coloniais e descoloniais. Para Philo e Wolch, as geografias animais também se cruzam com renovações importantes na teoria social contemporânea, sobretudo com a "crítica pós-colonial" (1998: 197). Wolch nota esse traço, afirmando que as novas geografias animais estão mesmo pautadas na "teoria pós-colonial e na teoria crítica da raça" (2002: 725). Parece existir trabalhos de geografia animal fundamentados em uma "ecologia política pós-colonial", na qual se procura explorar "como o tratamento de animais sob formas contemporâneas do capitalismo e/ou neocolonialismo demonstra o caráter socialmente injusto e ecologicamente perigoso dos modos de economia política neoliberal e de formas emergentes de livre mercado ambientalista" (LORIMER; SRINIVASAN, 2013: 333). Cruzando o feminismo vegano com a crítica pós-colonial, Emel e Wolch afirmam que o uso instrumentalista dos animais não-humanos se assemelha com o das populações negras submetidas ao regime colonial de escravidão nas Américas, sobretudo no que diz respeito ao "controle e tortura" (1995: 634). Na mesma linha, elas diagnosticam a racialização da carne, pela qual os comedores de carne vermelha se auto associam como "líderes do progresso" (Ibdem), utilizando-se do consumo especista da carne como um elemento de distinção social elitista e racista. Elder, Wolch e Emel viram que o etnocentrismo branco e nacionalista norte-americano afirma que somente sua prática especista (consumo de carne de bois, porcos, frango e peixe) é válida, operando uma "racialização pós-colonial" (1998: 80) do consumo de outras carnes e com outros métodos de abate, feito por culturas latinas e orientais. 
Temos aqui as reflexões em torno da Actor-Network Theory (ANT; Teoria Ator-Rede), muito famosa em função dos desenvolvimentos do sociólogo e filósofo francês Bruno Latour $(2004 ; 2011)$. Alguns setores das geografias animais buscam então "um desenvolvimento e extensão da teoria ator-rede para os animais, reconhecendo a sua agência em práticas da vida cotidiana" (LORIMER; SRINIVASAN, 2013: 336). Deste modo, "geógrafos usando a teoria ator-rede argumentavam que, analiticamente, não existia nenhuma distinção a priori a ser feita entre humanos e nãohumanos, que linhas entre pessoas, máquinas ou animais estão sujeitas a mudanças e negociações" (EMEL; WILBERT; WOLCH, 2002: 409). Nesse campo, as geografias animais de matriz britânica se destacam. Para Urbanik as geografias pautadas na ANT visam questionar os binarismos vindos da "Revolução científica e do Iluminismo e Modernismo", principalmente os "natureza/cultura, sujeito/objeto e humano/animal", afirmando assim a categoria de "hibridismo" como uma alternativa (2012: 41). Sarah Whatmore nota a volta da Geografia ao debate sobre a "Natureza" (2002: 2), tentando se desembaraçar da oposição natureza/cultura, como um esforço próximo das perspectivas da ANT e como um passo necessário para a construção de geografias híbridas. Todo um campo de pesquisas inspiradas na ANT "implantam um forte sentido nas relações espaciais" (PHILO; WOLCH, 1998) que se inserem nas redes de interações animais-humanas. "Existem espaços não-humanos? Existem espaços destinados a serem não-humanos? Se sim, como eles são e quais são suas consequências para a política" essas "questões de fronteira" (HINCHLIFE; et. al., 2002: 643) são umas das reflexões que as geografias híbridas têm se feito. Entretanto, é necessário salientar que importantes críticas a essa perspectiva já vêm sendo feitas, destacando-se principalmente as limitações estabelecidas na atribuição de agência a todas as "coisas", apagando assim importantes diferenças entre formas de vida, sobretudo entre as "sencientes e não-sencientes" (LORIMER; SRINIVASAN, 2013: 336).

Por fim, temos as ponderações próximas do movimento de Libertação Animal, significativo pela sua dimensão mais prática, como a Frente de Libertação Animal (ALF) e a Sea Shepherd (Pastores do Mar), dentre outros, e pela sua dimensão mais teórica representada pelos maiores eixos da Ética Animal contemporânea, a perspectiva utilitarista (SINGER, 2010) e a perspectiva deontológica (REGAN, 2006; FRANCIONE, 2000). É importante destacar que de forma mais intensa e engajada, ou não, quase a totalidade das críticas da geografia animal contemporânea parecem 
transitar por esse campo. Para Wolch, um dos fatores que explica a emergência dessa renovação nas geografias animais é a "ascensão de poderosos movimentos ambientais durante os anos 1970 e 1980" e "novas organizações trabalhando no interesse dos animais, como a PETA, ALF [...]" (2002: 725). Assim, "descentramentos" (DERRIDA, 2011: 410) éticos na Geografia Humana contemporânea promovidos pelas novas geografias animais estão totalmente inseridos nos rastros do Movimento e das Éticas Animais. É o caso de Lynn, por exemplo, que, extrapolando os limites acadêmicos e disciplinares da Geografia, nos propõe uma "Geoética" pautada nos princípios do "Geocentrismo", da "Igual Consideração de Interesses", dos "Casos Difíceis" e da "Capacidade de Cuidado Moral” (1998: 291-4). Um ponto de vista claramente influenciado pela perspectiva da ética animal de Singer. Emel e Wolch, afirmam que, no contexto acadêmico das Geografias Animais, "nós temos uma responsabilidade intelectual, como também um dever ético, em considerar intimamente a vida dos animais" (1998: XI). Wilbert identificou que nas novas geografias animais existe um chão comum que questiona "as relações de poder desiguais entre animais e pessoas" (2009: 124). Lorimer e Srinivasan (2013: 340) também notam a importância da Ética Animal para as geografias animais, mesmo que em um tom crítico, chamando a atenção para a necessidade de se renovar o debate para além das perspectivas de Singer e Regan.

\section{Quando as Bestas Começam a Falar: Crítica do Antropocentrismo em Geografia}

Como vimos, a crítica do conceito de natureza consistiu numa tarefa inicial das geografias animais. Entretanto, longe de estar perto de uma vitória epistêmica, as geografias animais se viram circunscritas por um especismo e antropocentrismo "molecular" (DELEUZE; GUATTARI, 2007) presente no campo da Geografia como um todo. Nesse sentido, as críticas antiespecistas vieram de toda parte. Entretanto, um questionamento contundente foi aquele direcionado contra as perspectivas do especismo no Planejamento Territorial, na Geografia Urbana e nas discussões mais amplas a respeito da Produção do Espaço.

Um ponto inicial que se destaca é o fato da urbanização no ocidente, como afirma Wolch, ser amplamente fundada na noção de progresso, revelando assim, o paradigma de "conquista e exploração da natureza pela 
cultura" (1998: 119). Entretanto, essa perspectiva, salvo raras exceções, parece estar imune a críticas no contexto dos estudos urbanos e de planejamento espacial na Geografia, e mais, essa perspectiva parece mesmo estar encarnada nessas geografias, tanto em sua face mais acadêmica/epistêmica, quanto naquela relativa aos geógrafos/ consultores. Assim, não deveríamos nos assustar quando nos damos conta que "na teoria vigente, a urbanização transforma terras 'vazias', através do processo chamado 'desenvolvimento', para produzir 'terras modernizadas"” (1998: 119). Wolch também denuncia o especismo que se exerce através de uma perversidade epistemológica da geografia urbana e do planejamento territorial, já que estes se utilizam de um léxico filosóficoconceitual que invisibiliza a vida selvagem e não-humana, justificando assim, o seu massacre através do vazio implícito da natureza colocado em suas categorias (1998: 119).

É notável como a formação territorial estadunidense se deu a partir dessa perspectiva denunciada pelas geografias animais, onde o especismo aparecia dentro de um "enunciado" (FOUCAULT, 2010: 119) que empregava uma cruzada genocidária contra a vida animal selvagem, ao mesmo tempo que negava essa vida em termos epistêmicos ao usar categorias vazias e abstratas, como natureza e ambiente. Esse foi o caso por exemplo da guerra contra os leões da montanha para a construção da moderna e urbana Santa Monica (CA): "A ideologia do crescimento urbano do pós-guerra nos Estados Unidos era predicativa quanto à habilidade das pessoas em controlar a natureza e excluir os animais selvagens da cidade" (GULLO; et. al., 1998: 139).

Existe, pois, uma crítica à cidade enquanto o lócus da produção especista do espaço, como já havíamos colocado anteriormente (LEAL, 2013a: 13), conjuntamente com a crítica direcionada à negligência da Geografia (urbana) diante desses problemas urbanos, já que "os animais têm sido amplamente excluídos do nosso entendimento do que é cidade e urbanismo" (WOLCH, 1998: 136 - grifos do autor).

Ecossistemas e espécies inteiras estão ameaçados, enquanto animais na busca por água ou comida arriscam-se entrando em áreas urbanas, onde encontram pessoas, veículos e outros perigos. A explosão da população de animais de criação não somente poluiu fontes de água, mas gerou um assassinato em massa de cães e gatos. O isolamento das populações urbanas dos animais domesticados que elas comem, distanciaram-nas 
dos horrores e perigos dos abatedouros industriais [...] Para a maioria das criaturas livres, assim como para um número absurdo dos escravos, o que de fato são os animais de companhia e de abate, as cidades significam sofrimento, morte ou extinção. (WOLCH: 1998: 120)

Outra questão que parece ter sido percebida por Philo e Wilbert é apresentada na proposição de que "a não ser que os animais apareçam em forma de comida, a insinuação é de que os animais devem definitivamente ficar 'fora' do perímetro da existência humana, banidos da vizinhança da vida cotidiana e de trabalho humano" (2000: 11). De uma forma mais completa, eles afirmam que:

\begin{abstract}
Apesar de agora ser, de certo modo, superutilizado, nos propomos a colocar em serviço mais uma vez o famoso termo de Said $(1978,54-55,71-71)$ 'geografias imaginativas', para sugerir que muitos dos discursos humanos contêm em si uma geografia imaginativa definida, que serve para posicioná-los (os animais) em relação a 'nós' (humanos), de uma forma que ligue uma 'outrização' conceitual (separando eles de nós em termos de traços de caráter) a uma 'outrização' geográfica (fixando eles em lugares do mundo e espaços diferentes daqueles que nós, humanos, tendemos a ocupar). (PHILO; WILBERT, 2000: 10-11).
\end{abstract}

Isso significa, antes de mais nada, que devemos repensar as práticas espaciais urbanas em termos de uma convivialidade e de um compartilhamento do espaço onde não se reproduzam as lógicas especistas e antropocêntricas. "Uma ética interespécie do cuidado, substitui o dominacionismo para criar regiões urbanas onde os animais não são encarcerados, assassinados ou mandados para viver em prisões selvagens distantes, mas ao contrário, são vizinhos valorizados e parceiros na sobrevivência" (WOLCH: 1998: 125) Não é por menos que Wolch nos traz a tarefa de construir uma "crítica do planejamento urbano enquanto parte do projeto modernista de controle e dominação dos outros (humanos, assim como não-humanos), através da construção racionalista da cidade e do policiamento das interações urbanas e proximidades animal/humano, em nome da saúde e do bem-estar humano" (WOLCH, 1998: 127-128). Tarefa essa, que deve passar também pela construção de uma "teoria urbana transespécie" (WOLCH; WEST; GAINES, 1995: 735). 


\section{Aberturas}

Como vimos anteriormente, aquilo que chamados de virada animal na Geografia Humana contemporânea é ainda muito recente. Se seus desafios, limites e contradições ainda são amplos, múltiplos e por vezes subanalisados, preferimos finalizar este artigo destacando as contribuições críticas que o campo pode fornecer.

Willian Lynn, por exemplo, nos oferece contribuições que extrapolam o âmbito acadêmico da Geografia. Trata-se da proposta de um novo paradigma ético a partir da crítica à exclusão especista dos animais não-humanos da comunidade moral humana, e propõe o conceito de Geoética, ao incorporar a natureza e os animais não-humanos na comunidade moral das sociedades industriais (1998: 281). Além da inclusão das formas de vida não-humanas na comunidade moral, a Geoética também foca nas dimensões e diferenciações socioespaciais, atentando para "entendimentos situados dos problemas morais" e, no que diz respeito "aos animais, a geoética direciona nossa atenção para os contextos compartilhados de todas as formas de vida" (LYNN, 1998: 282).

Para repensar os problemas da "produção especista do espaço" (LEAL, 2013a: 10) no contexto urbano, Wolch propõe a Zoópole como alternativa, isto é, um processo de "reencantamento" e "renaturalização" da cidade de modo que essa se torne um espaço atrativo, e não hostil, para as formas de vida não-humanas (1998: 124). Do mesmo modo, a zoópole convida a uma "crítica da urbanização contemporânea, a partir do ponto de vista dos animais [...]" (1998: 135). Na mesma linha, radicalizando as reflexões a respeito das fronteiras animal/humano, de suas espacialidades e diferenças culturais e do papel ético de uma geografia não-especista, Wolch tece importantes reflexões:

Pensando prospectivamente a respeito da moralidade, animais e locais urbanos, meu trabalho exigiu uma reconceitualização das formas pelas quais a divisão animal/humano opera em termos de práticas éticas de vida e planejamento urbano. Algo muito importante aqui é a subjetividade animal: uma vez que abandonamos a estrita fronteira animal/humano, na qual temos os sujeitos humanos de um lado e animais objetos do outro, nós nos vemos obrigados a enquadrá-los em nossas considerações éticas e práticas cotidianas (WOLCH, 2002: 734). 
É interessante também ver a abordagem de Whatmore, Hinchliffe, et. al. a respeito do estranho contexto da adaptação das ratazanas d'água ao hostil ambiente da Londres urbana. Ao se engajarem num "experimento cosmopolítico", para vivenciar e entender mais o mundo das ratazanas d'água, os autores deram passos na direção de "expandir o mundo das ratazanas d'água" para a inteligibilidade dos "colegas" geógrafos, além de repensar as potências epistêmicas e éticas dos "espaços não-humanos" (2005: 656).

A forte crítica aos paradigmas especistas e antropocêntricos - que invisibilizam as potências e multiplicidades animais encarcerando-os em um estatuto moral privados de agência e subjetividade, também é um ponto forte das geografias animais. Animais selvagens, por exemplo, que ousam ultrapassar os limites e adentrar em territórios supostamente humanos, engajando-se em práticas de "transgressão", podem ser assassinados por represália, já que, ao invadirem o espaço supostamente humano, tornam-se "deslocados", e por terem uma condição social abjeta podem ser exterminados (PHILO; WILBERT, 1998: 110). Wilbert afirma que "as relações de poder desiguais entre animais e humanos" e a agência animal não-humana nos é o suficiente para podermos pensar os animais como um "grupo social marginalizado" (2009: 124). Wilbert e Philo nos falam que alguns animais possuem a capacidade de "transgredir os ordenamentos espaciais construídos material e imaginativamente das sociedades humanas" (2000: 15).

Griffiths, et. al. apontam para o aspecto de "resistência" dos gatos, que renegam ou subvertem características básicas da espacialidade urbana humana - ao desenvolverem práticas noturnas, de territorialidades cíclicas e não-gregárias, subverterem os limites de público-privado -, a ponto de se referirem a eles como "parcialmente domesticados". O mesmo estudo de Griffiths, et. al. atesta esse fato ao acompanhar gatos ferais na Inglaterra, que constroem territorialidades em zonas industriais abandonadas pela gentrificação, em cemitérios ou em bairros periféricos residenciais, mostrando, ao mesmo tempo, a transgressão e a resistência desses gatos às normas e lógicas espaciais humanas, e a sua interface na construção de espaços compartilhados transespécie (2000: 58).

Quanto ao nosso projeto, trata-se de uma cidade cujos moradores tentem reincorporar os animais selvagens nas questões humanas cotidianas, ao respeitar seu valor e sua dignidade, ao aceitar a tarefa de conhecer suas formas de 
vida, e ao encarar os riscos associados em compartilhar a Terra com formas de vida mais velhas - e talvez mais sábias que nós. (WOLCH; et. al. 1995: 735).

Como havíamos colocado anteriormente, as geografias animais são recentes porém suas contribuições já são abundantes. De modo que, nosso objetivo aqui foi somente o de dar uma nota introdutória, parcial e limitada a respeito de alguns temas e aspectos de suas discussões, os quais julgamos mais pertinentes. Que essas contribuições inspirem um repensar/refazer radical a respeito do papel dos animais não-humanos e dos humanos na construção das relações interespecíficas - ainda brutalmente antropocêntricas e especistas - do ponto de vista de sua geograficidade.

SOBRE BESTAS E MAPAS: NOTAS INTRODUTÓRIAS SOBRE A VIRADA ANIMAL NA GEOGRAFIA HUMANA CONTEMPORÂNEA

Resumo: Nas últimas três décadas os Animal Studies (Estudos Animais) têm chamado bastante atenção dentro do largo campo das ciências humanas. O reflexo disso na geografia se dá com a construção recente daquilo que Julie Urbanik (2012) chama de nova geografia animal, sobretudo no contexto anglo-saxônico a partir dos anos 1990. Partindo de uma crítica genealógico-desconstrutora, inspirada nos rastros de Jacques Derrida, como também de Gilles Deleuze \& Félix Guattari e de Michel Foucault, procuramos oferecer uma base introdutória do campo. Assim, levamos a cabo uma investigação de arquivo, onde não foram priorizados autores, conceitos ou métodos, mas as temáticas em que perpassavam os animais nessas novas geografias. Palavras-chave: geografias animais, ética animal, especismo, genealogia, desconstrução.

BEASTS AND MAPS: AN INTRODUCTION TO THE ANIMAL TURN IN CONTEMPORARY HUMAN GEOGRAPHY

Abstract: In the last three decades, Animal Studies have gain attention within the broad field of Humanities. We can see reflection of this in geography with the recent construction of what Julie Urbanik (2012) calls the New Animal Geography, especially in Anglo-Saxon context from the 1990s. Starting from a genealogical-deconstructive critic, inspired by the 
path of Jacques Derrida as well as Gilles Deleuze, Felix Guattari and Michel Foucault, we seek to offers some introductory basis in this new field. So, we started an archive's investigation, where the author, concepts or methods were not prioritized, but the thematic aspects that involves animals in these new geographies.

Keywords: animal geographies, animal ethics, speciesism, genealogy, deconstruction.

\section{BIBLIOGRAFIA}

ADAMS, C. J. (2012) A Política Sexual da Carne: A Relação entre o Carnivorismo e a Dominância Masculina. São Paulo: Alaúde Editorial.

ANDERSON, K. (1998) Animals, Science and Spectacle in the City. In: WOLCH, J.; EMEL, J (Org.). Animal Geographies: Place, Politics and Identity in the Nature-Culture Borderlands. London: Verso.

- (1997) A Walk on the Wild Side: A Critical Geography of Domestication in 1997. Progress in Human Geography, vol. 21(4), pp. 463-85.

BRAIDOTTI, R. (2006) Transpositions: On Nomadic Ethics. Cambridge: Polity Press.

BRUNHES, J. (1962 [1924]) A Geografia Humana. Rio de Janeiro: Editora Fundo de Cultura.

CAPEL, H. (1983 [1981]) Filosofia y Ciencia em la Geografia Contemporánea. Barcelona: Editorial Barcanova.

- (1989 [1987]) Geografia Humana y Ciencias Sociales: Uma perspectiva histórica. Barcelona: Montesinos Editor.

CLAVAL, P. (1974) Evolucion de la Geografia Humana. Barcelona: Oikos-tau ediciones.

. (2006) História da Geografia. Lisboa: Edições 70.

DELEUZE, G.; GUATTARI, F. (2003) Kafka: Por uma literatura menor. Lisboa: Assírio e Alvin. 
Editora 34.

. (2010) Anti-Édipo: Capitalismo e Esquizofrenia I. São Paulo:

. (2007) Mil Planaltos: Capitalismo e Esquizofrenia II. Lisboa:

Assírio e Alvin.

. (2009) O que é a filosofia? Rio de Janeiro: Editora 34.

DERRIDA, J. (2011) Escritura e Diferença. São Paulo: Perspectiva.

. (2002) O animal que logo sou. São Paulo: EdUNESP.

. (2001) Posições. Belo Horizonte: Autentica.

. (2004) De que Amanhã... Diálogo (Com Roudinesco, E.). Rio de Janeiro: Jorge Zahar Editor.

ELDER, G. WOLCH, J. EMEL, J. (1998) Le Pratique Sauvage: Race, Place and Human-Animal Divide. In: WOLCH, J.; EMEL, J (Org.). Animal Geographies. Place, Politics and Identity uin the Nature-Culture Borderlands. London: Verso.

EMEL, J. (1998) Are You Man Enough, Big and Bad Enough? Wolf Eradication in the US. In: WOLCH, J. e EMEL, J (Org.). Animal Geographies. Place, Politics and Identity uin the Nature-Culture Borderlands. London: Verso.

. WILBERT, C.; WOLCH, J. (2002) Animal Geographies. Society \& Animals. Leiden: Koninklijke Brill NV, 10:4.

FOUCAULT, M. (2012a) Nietzsche, Genealogia e História. In: Microfisica do Poder. São Paulo: Editora Graal Ltda.

. (2012b [1970]) A Ordem do Discurso. São Paulo: Edições Loyola.

. (1967 [1966]) As Palavras e as Coisas. São Paulo: Martins

Fontes.

Universitária.

. (2010 [1969]) A Arqueologia do Saber. Rio de Janeiro: Forense

FRANCIONE, G. (2000) Introduction to Animal Rights: Your Child or the Dog. Philadelphia: Temple University Press. 
GRIFFITHS, H; POULTER, I; SIBLEY, D. (2000) Feral cats in the city. In: PHILO, C.; WILBERT, C. (Org.) Animal Spaces, Beastly Places: New Geographies of Human-Animal Relations. London e New York.

GRIFFIN, C. J. (2010) More-than-human histories and the failure of grand state schemes: sylviculture in the New Forest, England. Cultural Geographies. 17(4), 451-472.

GULLO, A. Lassiter, U. WOLCH, J. (1998) The Cougar's Tale. In: WOLCH, J.; EMEL, J (Org.). Animal Geographies. Place, Politics and Identity in the Nature-Culture Borderlands. London: Verso.

HARAWAY, D. (1995) Ciência, Cyborgs y Mujeres: La Reinvencion de La Naturaleza. Madrid: Ediciones Cátedra.

HARRISON, Paul. (2006) Post-structuralist Theories. In: AITKEN, S.; VALENTINE, G. (ed.). Approaches to Human Geography. London: Sage, pp. 122-135.

HINCHLIFFE, S.; KEARNES, M. B.; DEGEN, M.; WHATMORE, S. (2005) Urban wild things: a cosmopolitical experiment. Environment and Planning D: Society and Space, volume 23, pp. 643 - 658.

HINCHLIFFE, S. (2007) Geographies of Nature: Societies, Environments, Ecologies. London: Sage.

LEFF, E. (2006) Racionalidade Ambiental: A reapropriação social da natureza. Rio de Janeiro: Editora Civilização Brasileira.

LACOSTE, Y. (2009) A Geografia: Isto Serve, em Primeiro Lugar, Para Fazer a Guerra. São Paulo: Papirus.

LATOUR, B. (2011) Jamais Fomos Modernos. São Paulo: Editora 34.

(2004) Políticas da Natureza: Como Fazer Ciência na Democracia. Bauru: Edusc.

LEAL, P.C. (2011) Anarquia, Ecologia e Veganismo: Contribuições de Élisée Reclus para uma Visão Bioética do Espaço. In: Anais do Colóquio Internacional Eliseé Reclus e o Novo Mundo. Disponível em: http://redebrasilis.net/MemoriasReclusSP2011/campos.pdf

(2013a) Antrópole: Esboço para uma Crítica da Produção Especista do Espaço. In: Anais do XIII Simpurb, UERJ, Rio de Janeiro. 
Disponível

em:

http://www.simpurb2013.com.br/wpcontent/uploads/2013/11/GT10-1110-Pablo.pdf. Acessado em: 4 jan. 2014.

. (2013b) As Fronteiras do Especismo: Materiais Preliminares para uma Análise do Status Moral dos Animais Não-Humanos na História da Geografia Humana Clássica. In: Anais do X Congresso Brasileiro de Bioética. pp. 309.

LYNN, W. S. (1998) Animals, Ethics and Geography. In: WOLCH, J. e EMEL, J (Org.). Animal Geographies: Place, Politics and Identity in the Nature-Culture Borderlands. London: Verso.

LORIMER, J; SRINIVASSAN, K. (2013) Animal Geographies. In: JOHNSON, N C.; SCHEIN, R. H.; WINDERS, J. The Wiley-Blackwell Companion to Cultural Geography. Published by John Wiley \& Sons Ltd.

MICHEL, S. M. (1998) Golden Eagles and the Environmental Politics of Care. In: WOLCH, J.; EMEL, J (Org.). Animal Geographies: Place, Politics and Identity in the Nature-Culture Borderlands. London: Verso.

NIETZSCHE, F. (2008) Humano, Demasiado Humano II. São Paulo: Companhia das Letras.

Companhia das Letras.

. (2008) Genealogia da Moral: Uma polêmica. São Paulo:

PHILO, C. (1998) Animals, Geography and the City: Notes on Inclusions and Exclusions. In: WOLCH, J.; EMEL, J (Org.). Animal Geographies. Place, Politics and Identity. In: The Nature-Culture Borderlands. London: Verso.

PHILO, C.; WILBERT, C. (Org.) (2000) Animal Spaces, Beastly Places: New Geographies of Human-Animal Relations. London and New York.

. (2000) Animal Spaces, Beastly Places: An Introduction. In: PHILO, C.; WILBERT, C. (Org.) Animal Spaces, Beastly Places: New Geographies of Human-Animal Relations. London and New York.

PHILO, C; WOLCH, J. (1998) Through the Geographical Looking Glass: Space, Place, and society-Animal Relations. (Guest Editors Introdction). Society and Animals. Vol. 6, num. 2.

QUAINNI, M. (2002) Marxismo e Geografia, Rio de Janeiro: Paz e Terra. 
RATZEL, F. (1914 [1882]) Geografia dell'uomo (Antropogeografia). Torino: Fratelli Bocca.

RECLUS, E. (1984) El Hombre y La Tierra. [Giblin, B. (Org.)] Barcelona: Editora Efe.

REGAN, T. (2006) Jaulas Vazias: Encarando o Desafio dos Direitos Animais. Porto Alegre: Lugano.

SAUER, C. (1952) Seeds, Spades, Hearths and Herds. New York: American Geographical Society.

SIMOONS, F.J., SIMOONS, E.S. (1968) A Ceremonial Ox of India: The Mithan in Nature, Culture and History. Wisconsin: University of Wisconsin Press.

SINGER, P. (2010) Libertação Animal. SP: WMF Martins Fontes.

SMITH, N. (1988) Desenvolvimento Desigual: Natureza, Capital e a Produção do Espaço. Rio de Janeiro: Bertrand Brasil.

TUAN, Y. (1984) Dominance and Affection: The Making of Pets. Yale: Yale University Press.

. (2012) Topofilia: Um Estudo da Percepção, Atitudes e Valores do Meio Ambiente. Londrina: Eduel.

URBANIK, J. (2012) Placing Animals: An Introduction to the Geography of Animal-Human Relations. England: Rowman and Littlefield Publishers Inc.

VIDAL DE LA BLACHE, Paul. (1946 [1922]) Principios de Geografia Humana. Lisboa: Edições Cosmos.

WHATMORE, S. (2001) Hybrid Geographies: Natures Cultures Spaces. London: SAGE Publications Ltd.

. (1999) Hybrid geographies: Rethinking the "human" in human geography. In: MASSEY, D.; ALLEN, J.; SARRE, P. (ed.) Human Geography Today. Cambridge: Polity, pp. 22-39.

WILBERT C. (2009) Animal Geographies. In: KITCHIN, R., THRIFT, N. (ed.) International Encyclopedia of Human Geography. Oxford: Elsevier, volume 1, pp. 122-126 
. (2007) The Birds, The Birds: Biopolitics and Biosecurity in the Contested Spaces of Avian Flu. Focas Forum On Contemporary Art \& Society. Singapore: NUS Press, vol. 6, pp.102-123.

WOLCH, J. (1998) Zoopolis. In: WOLCH, J.; EMEL, J (Org.). Animal Geographies. Place, Politics and Identity in the Nature-Culture Borderlands. London: Verso.

- (2002) Anima Urbis. Progress in Human Geography. Los Angeles: Sage, 26(6), pp. 721-742

WOLCH, J, WEST, K. e GAINES, T. (1995). Transspeiciest Urban Theory. Environment and Planning D: Saciety and Space, volume 13 (6), pages $735-760$

WOLCH, J. e EMEL, J. (1998) Preface. In: Geographies. Place, Politics and Identity in the Nature-Culture Borderlands. London: Verso.

. (1998) Witnessing the Animal Moment. In: WOLCH, J.; EMEL, J (Orgs.). Animal Geographies. Place, Politics and Identity in the NatureCulture Borderlands. London: Verso.

. (1995) Bringing the Animals Back. Environment and Planning D: Society and Space, volume 13, pages. 632-636.

Data de submissão: 25/01/2014

Data de aprovação: 20/06/2014 